\title{
IMPLEMENTASI TOTAL QUALITY MANAGEMENT (TQM) MELALUI BUDAYA KUALITAS
}

\author{
Sri Hartini \\ Email : sri hartini@gmail.com
}

STIE Palangka Raya

\begin{abstract}
Total QualityManagement (TQM) is a new paradigm in running a business with the goal to maximize organizational competiveness through focuses on consumer satisfaction, all employee engagement, and sustainable improvement on quality of products, services, human, process and organizational environment.

This research aims to determine the amount of effects by variables in the implementation of Total QualityManagementconsisting of:focuses on consumers, sustainable improvement, management commitment, training, employee empowering, performance comparison, and use of simultaneous statistic equipment on quality culture.

The research method uses type of explanatoryresearch with quantitative approach because it tries to describe inter-variable correlation through hypothesis testing, meanwhile in general, the data used are in the form of number calculated by statistic test.

Results of the research are (a) Simultaneously the variables in the implementation of TotalQuality Managementare able to describe the effects on the quality culture variable by $63,5 \%$, meanwhile the remaining is described or influenced by other independent variables beyond the research model equation. Inter-variable correlation in the implementation of TotalQuality Management on the quality culture is quite strong (b) There are significant effects between variables in the implementation of Total QualityManagementconsisting of focuses on employee, management commitment, training, employee empowering, and use of statistic devices partially on quality culture variable, meanwhile the sustainable improvement and performance comparison do not influence significantly on quality culture variable. Thus, the second hypothesis of this research is rejected (c) The training variable provides dominant effects on the quality culture variable. Thus the third hypothesis of this research is rejected.
\end{abstract}

Keywords: TQM, performance, quality culture 


\section{PENDAHULUAN}

Total Quality Management (TQM) adalah sistem pengendalian mutu yang didasari pada filosofi adalah pemenuhan kebutuhan pelanggan dengan sebaik-baiknya. Kebutuhan pelanggan tersebut harus melebihi keinginan pemakai jasa/produk. Persaingan pasar global dewasa ini, tuntutan konsumen atas peningkatan kualitas produk dan jasa bertambah. Terjadi pula peningkatan penawaranprodukdan jasa denganhargalebihbersaing darinegaradenganbiaya tenaga kerja rendah (Dale,2003)

Membangun kinerja menghadapi tantangan persaingan tersebut adalah melalui perbaikan berkelanjutan padaaktivitas bisnis yang terfokus pada konsumen, meliputi keseluruhan organisasi dan penekanan pada fleksibilitas dan kualitas (Krajewski,Lee,dan Ritzman, 1999).

Organisasi mampu merespon permintaan pasar atas kualitas produk, jasa dan proses yang telah dikembangkan secara meluas selama dua decade terakhir.

Tujuan penelitian (1) Untuk mengetahui seberapa besar pengaruh variabel-variabel dalam implementasi Total QualityManagement meliputi (a) focus pada konsumen (b) perbaikan berkelanjutan, komitmen manajemen (c) pelatihan, pemberdayaan karyawan, perbandingan kinerja pada Perusahaan Samsung Indonesia.

\section{TINJAUAN PUSTAKA}

Kajian teoritis dan empiris menunjukkan bahwa ada beberapa persamaan maupun perbedaan diantara faktor-faktor kritis TQM yang mempengaruhi keberhasilan implementasi TQM yang telah dikemukakan oleh beberapap akar maupun peneliti terdahulu, tetapi secara substansial dapat ditarik benang merahnya. Penggunaan faktor-faktor kritis TQM 
dalam penelitian-penelitian tersebut juga menunjukkan pengaruh yang beragam terhadap kinerja individu maupun organisasi.

Faktor-faktor kritis TQM yang dikemukakan oleh Huarng dan Yao (2002) lebih komprehensif dibandingkan dengan yang lain karena mereka memadukan keseimbangan antara softand hard side (Jabnon dan Sedrani, 2005:9). Oleh karena itu penelitian ini terutama menggunakan faktor-faktor kritis tersebut mengingat lokasi penelitian sama-sama negara di kawasan Asia (Taiwan), sedangkan penelitian sejenis yang dilakukan di Indonesia masih terbatas. Faktor-faktor kritis kemudian dimodifikasi dengan model penelitian yang telah dilakukan oleh Jabnon dan Sedrani (2005) dan Srismith (2005), selain karena mereka menambahkan variabel dimensi budaya, penelitian ini juga dilakukan di kawasan Asia (United Arab Emirates/UAE dan Thailand).

Modifikasi model Huarng dan Yao (2002), Jabnoun dan Sedrani (2005), dan Srismith (2005) tersebut menghasilkan tujuh variabel implementasiTQM yang digunakan dalam penelitian ini, yaitu: focus pada konsumen, perbaikan berkelanjutan, komitmen manajemen, pelatihan, pemberdayaan karyawan, perbandingan kinerja, dan penggunaan piranti statistik.

Dari kajian teoritis dan empiris sebelumnya juga diketahui bahwa diantara ke tujuh variabel implementasi TQM tersebut secara umum yang berpengaruh dominan terhadap keberhasilan implementasi TQM adalah variabel komitmen manajemen sebagaimana pendapat beberapa pakar kualitas, antara lain: Hashmi (2004), Curkovic dan Landeros (2000), dan Paskard (1995), juga didukung hasil penelitian yang dilakukan oleh: Dayton (2003), Baidoun (2003), Munizu (2003), dan Metri (2005). Oleh karena 
itu, penelitian ini juga menggunakan hipotesa bahwa komitmen manajemen mempunyai pengaruh yang dominan terhadap budaya kualitas.

Penelitian terdahulu yang mengkaitkan implementasi TQM dengan fenomena budaya organisasi secara umum masih terbatas pada studi tentang pengaruh budayaorganisasi terhadap keberhasilan maupun kegagalan implementasi TQM, bukan sebaliknya apakah implementasi TQM mampu mempengaruhi, mengubah bahkan membentuk budaya organisasi sebagaimana pendapat beberapa pakar kualitas. Pendekatan budaya organisasi yang dilakukan juga masih terbatas pada level pertama (Artefacts and Creation) dan level kedua (Values and Beliefs).

Tinjauan teoritis diketahui bahwa implementasi TQM dapat merubah orientasi budaya suatu organisasi menuju budaya kualitas yang merupakan salah satu indikator keberhasilan implementasi TQM danpada akhirnya dapat meningkatkan daya saing organisasi Cortada, (1993) Goetsch dan Davis dalam Tjiptono dan Diana, (2003) Hardjosoedarmo (2005) dan Metri, 2005) Dilainpi hak menuru tHardjosoedarmo (2004), dalam hal kualitas, apabila organisasi hanya mencapai wujud nyata saja (level pertama), maka yang diperoleh hanyalah "cosmetic quality" saja. Untuk mencapai internalisasi kualitas maka organisasi perlu bertumpu pada level ketiga yaitu asumsi dasar (BasicAssumption)..

Oleh karena itu, terdapat perbedaan mendasar antara penelitian ini dengan penelitian-penelitian sebelumnya, yaitu: meneliti pengaruh implementasi TQM terhadap budaya kualitas (bukan sebaliknya), dan menggunakan model budaya menurut Kujala dan Ullrank (2004) yang diadopsi dari level budaya organisasi menurut Schein, karena lebih komprehensif, terbaru, dan terfokus pada budaya kualitas (TQM basic assumptions and corevalues). 


\section{METODE PENELITIAN}

Penelitian tentang Implementasi Total Quality Management berbasis budaya kualitas ini termasuk jenis penelitian explanatory dengan pendekatan kuantitatif yang menjelaskan hubungan antara variabelvariabel melalui pengujian hipotesis, data yang digunakan secara umum berupa angka-angka yang dihitungmelalui uji statistik.

Penelitian menggunakan analisis inferensial untuk menguji pengaruh antara variabel-variabel dalam implementasi TQM terhadap variabel budaya kualitas, dan menguji hipotesis yang telah dirumuskan. Model analisisyang digunakana dalah regresi linier berganda dengan menggunakan bantuan perangkat lunak komputer (software) program SPSS (Statistical Product and ServiceSolutions) versi 26.0 for Windows, dengan rumus sebagai berikut:

$$
Y=\beta_{0}+\beta_{1} X_{1}+\beta_{2} X_{2}+\beta_{3} X_{3}+\beta_{4} X_{4}+\beta_{5} X_{5}+\beta_{6} X_{6}+\beta_{7} X_{7}+\varepsilon
$$

Keterangan:

$\mathrm{Y} \quad=$ Budayakualitas

$\beta_{0} \quad=$ Konstanta(intersep)

$\beta_{1 . .} \beta_{7} \quad=$ Koefisienregresi

$\mathrm{X} 1=$ Fokuspadakonsumen

X2 = Perbaikanberkelanjutan

$\mathrm{X} 3=$ Komitmenmanajemen

X4 $=$ Pelatihan

X5 $=$ Pemberdayaankaryawan

$\mathrm{X} 6=$ Perbandingankinerja

$\varepsilon=$ Kesalahanpengganggu

\section{HASIL PENELITIAN}

\section{Pengaruh Simultan}

Hasil pengujian hipotesis pertama menunjukkan bahwa variabelvariabel dalam implementasi Total Quality Management (TQM) secara simultan mempunyai pengaruh yang signifikan berbasis budaya kualitas. 
Hal ini dapat diinterpretasikan bahwa implementasi TQM yang didokumentasikan dalam klausul-klausul ISO 9001:2000 dan diterapkan kurang lebih selama sepuluh tahundi Maspion Group telah mampu membentuk dan merubah orientasi budaya organisasi menjadi budaya kualitas.

Kedelapan prinsip TQM yang tertera dalam klausul-klausul ISO 9001:2000 tersebut diantaranya adalah: focus organisasi pada konsumen, kepemimpinan, keterlibatan karyawan, pendekatan proses, pendekatan sistem pada manajemen, perbaikan berkelanjutan, pendekatan factual dalam pengambilan keputusan, kemitraan yang saling menguntungkan.

Hasil penelitian tersebut mendukung pendapat beberapa pakar kualitas, diantaranya: implementasi TQM dapat merubah orientasi budaya suatu organisasi menuju budaya kualitas (Cortada, 1993; Goetsch dan Davis dalam Tjiptono, 2003; dan Hardjosoedarmo, 2005) ;budaya kualitas dipertimbangkan sebagai salah satu hal yang terpenting sebagai indikator keberhasilan implementasi TQM (Metri, 2005); dan studi empiris: TQM efektif mengembangkan elemen budaya kualitasdan budaya tersebut menunjang keberhasilan perbaikan proses (Gore, 1999); integrasi filosofi dengan piranti TQM berpengaruh signifikan terhadap kinerja bisnis (Huarng dan Yao, 2002).

Menurut teori Schein (1985), budaya dibangun dalam tiga level. Level pertama adalah wujud nyata yang meliputi kegiatan dan kejadian sebagai hasil pemikiran (Artefacts and Creation), Level kedua adalah nilainilai dan keyakinan (Values and Beleifs), dan level ketiga adalah asumsi dasar yang merupakan pandangan terhadap masalah (Basic Assumption). Selanjutnya menurut Hardjosoedarmo (2004), dalam hal kualitas, apabila organisasi hanya atau baru mencapai wujud nyata saja (level pertama), 
maka yang diperoleh hanyalah "cosmeticquality" saja. Untuk mencapai internalisasi kualitasmaka organisasi perlu bertumpu pada asumsi dasar (BasicAssumption) tentang perlunya kualitas demi kelangsungan hidup dan perkembangan kehidupannya yang dikenal dengan budaya kualitas (Kekale,1999; KujaladanUllrank, 2004).

Nilai rata-rata setiap variabel bebas: focus pada konsumen, perbaikan berkelanjutan, komitmen manajemen, pelatihan, pemberdayaan karyawan, perbandingan kinerja,dan penggunaan piranti statistik, dan variabel terikat: budaya kualitas yang cenderung tinggi, membuktikan bahwaaktivitasimplementasi TQM cukup tinggidansecarasimultan mampu membangunbudayakualitasyang tinggi pula.

\section{Pengaruh Persial}

Nilai rata-rata variabel komitmen manajemen yang tertinggi $(4,49)$ dan nilai rata-rata variabel pemberdayaan karyawan yang terendah $(3,73)$, menunjukkan bahwa komitmen manajemen merupakan aktivitas yang relative paling menonjol dan pemberdayaan karyawan merupakan aktivitas yang kurang menonjol jika dibandingkan dengan aktivitas yang lain pada implementasi TQM.

Hasil pengujian hipotesis kedua menunjukkan bahwa secara parsial hanya variabel: focus pada konsumen, komitmen manajemen,pelatihan, pemberdayaan karyawan, dan penggunaan piranti statistic yang berpengaruh signifikan berbasis budaya kualitas, sedangkan variabel lainnya tidak berpengaruh signifikan berbasis budaya kualitas. Hasil penelitian ini mendukung penelitian sebelumnya, bahwa: filosofi TQM dan piranti TQM secara parsial tidak berpengaruh signifikan terhadap kinerja bisnis (Huarng dan Yao, 2002); tidak semua variabel-variabel dalam 
implementasi TQM mempunyai korelasi yang signifikan terhadap dimensi budaya organisasi (Jabnoun dan Sedrani, 2005).

\section{Pengaruh Dominan}

Hasil penelitian juga menunjukkan bahwa jika dibandingkan dengan variabel- variabel bebas yanglain, variabel pelatihan mempunyai pengaruh yang dominan terhadap variabel budaya kualitas. Hasil penelitian tersebut menolak atau bertentangan dengan pendapat Paskard (1995), Curkovicdan Landeros (2000), dan Hashmi (200), yang menyatakan variabel komitmen manajemen terhadap kualitasdan kepemimpinan merupakan variabel yang paling dominan menentukan keberhasilan implementasi TQM.

Menurut Lawson (2004) dalam perspektif sistem kualitas, manajemen puncak mempunyai pengaruh yang paling signifikan terhadap budaya kualitas. Apa yang mereka katakandan lakukan (atau tidak dilakukan) maupun dukungan akan direfleksikan dalam organisasi. Manajemen puncak mendefinisikan idealismenya kedalam misi,visi,nilai-nilaidan kebijakan, secara keseluruhan menjadi referensi bagi karyawan sebagai asset yang bernilai.

Menurut Paskard (1995),Kepemimpinanadalahelemen kunci keberhasilan implementasi TQM. Pemimpin mempunyai perspektif jangka panjang dan harus mampu memotivasi bawahan. Hal tersebut diperlukan dalam menegakkan budaya oganisasi yang dilengkapi dengan TQM. Hasil penelitian juga menolakatau bertentangan denganhasil penelitian terdahulu yang telah dilakukan oleh: Dayton (2003), Baidoun (2003), Munizu (2003), dan Metri (2005), dan menyimpulkan bahwa komitmen atau dukungan manajemen merupakan variabel yang berpengaruh dominan terhadap keberhasilan implementasi TQM. 
Variabel pelatihan relatif lebih rendah $(4,02)$ daripada nilai rata-rata tertinggi variabel: komitmen manajemen $(4,49)$, ternyata aktivitas pelatihan yang dilakukan oleh perusahaan lebih efektif memberikan kontribusi yang dominan dalam membentuk budaya kualitas jika dibandingkan dengan variabel-variabel implementasi TQM lainnya. Oleh karena itu, variabel pelatihan hendaknya dijadikan pertimbangan utama pihak manajemen dalam meningkatkan budaya kualitas.

\section{KESIMPULAN}

a. Terdapat pengaruhyang signifikan antara variabel-variabel dalam implementasi Total Quality Management yang terdiri dari: focus pada konsumen, perbaikan berkelanjutan, komitmen manajemen, pelatihan, pemberdayaan karyawan, perbandingan kinerja, terhadap budaya kualitas. Dengan demikian hipotesis pertama penelitian ini diterima.

b. Secara simultan variabel-variabel dalam implementasi Total Quality Management tersebut mampu menjelaskanpengaruhnya terhadapvariabel berbasis budaya kualitas 63,5\%, sedangkan sisanya dijelaskan atau dipengaruhi oleh variabel bebas lain diluarp ersamaan model penelitian. Korelasi antara variabel-variabel dalam membangun implementasi Total Quality Management terhadap budaya kualitas juga cukup kuat.

c. Terdapat pengaruh yang signifikan antara variabel dalam implementasi Total Quality Management yang terdiri dari: focus pada konsumen, komitmen manajemen, pelatihan, pemberdayaan karyawan secara parsial terhadap variabel budaya kualitas, sedangkan variabel perbaikan berkelanjutan dan perbandingan kinerja tidak berpengaruh secara signifikan terhadap variabel budaya kualitas. Dengan demikian hipotesis kedua penelitian ini ditolak. 
d. Variabel pelatihan mempunyai pengaruh yang dominan terhadap variabel budaya kualitas. Dengan demikian hipotesis ketiga penelitian ini ditolak.

\section{DAFTAR PUSTAKA}

Amar, Kiyafah \& Zuraidah Mohd Zain.(2001). Barriers in the Implementation of Total Quality Management in Indonesian Manufacturing Organizations. Jurnal Teknik Industri, Vol. 3, No. 2, Desember 2001

Dowling, P. \& Welch, D. E. (2004) International Human Resource Management: Managing People in a Multinational Context 4th edition, London UK, Thomson Learning.

Dowling, Peter J, Marion Festing and Allen D. Engle, 2008. International Human Resource Management : Managing People in a Multinational Context : Fifth Edition, South- Western Cengage Learning, United Kingdom

Gaspersz, Vincent. 2001. Total Quality Management. Jakarta : Gramedia Pustaka Utama.

Handayani, 2005. Kaizen Culture, Education and Training, New York: Irwing Professional.

Hitoshi Takeda, 2006. The Change Management Handbook, New York: Irwing Professional

Horngren, Charles T., George Foster., Srikant M. Datar. 2000. Cost Accounting: A Managerial Emphasis. International Edition.

Jurnal Akuntansi Vol.4 No.2 November 2012: 175-186. Pengaruh Penerapan Total Quality Management (TQM) dan Komitmen Organisasi terhadap Kinerja Perusahaan dengan Budaya Organisasi Sebagai Variabel Moderasi (Survei pada Perusahaan Manufaktur di Jawa Barat yang Listing di BEI)

Jurnal Akuntansi, Vol. 1, No. 2, April 2013 : 213-226. ISSN 2337-4314. Pengaruh Total Quality Management Terhadap Kinerja Financial (Study Pada Perusahaan Jasa di Kota Pekanbaru Provinsi Riau)

Krajewski, J. Lee and P. R. Larry, 2006, Operations Management Strategy and Analysis, Fifth Edition, Addison-Wesley Publising Company Inc.

Kujala, J., \& Lillrank, P. (2004). Total quality management as a cultural phenomenon. Quality Management Journal, 11(4), 43-55.

Pamungkur, 2011, Membangun Strategi Manajemen Peningkatan Mutu Pendidkan melalui Implementasi TQM, Tesis MM Undip Semarang 
Prajogo, Daniel. I., and Brown, A. 2004. "The Relationship Between TQM Practice and Quality Performance and the Role of Formal TQM Programs: An Australian Empirical Study". Quality Management Journal. 11 (4), pp.31-42

Sisnuhadi. (2014). The Relationship between Soft Factors and Hard Factors of TQM Practices and Organizational Learning. European Scientific Journal, March 2014 edition, Vol. 10, No. 7.

The Influence of Total Quality Management (TQM) Applications to Sales Raising at PT. Kereta Api Indonesia (Persero) Bandung The 2nd Operations Area. ISBN: 978-979-99365-7-8.

Kujala, J., \& Lillrank, P. (2004). Total quality management as a cultural phenomenon. Quality Management Journal, 11(4), 43-55.

Lincoln, J. R. (1989). Employee work attitudes and management practice in the US and Japan. California Management Review (Fall), 89-106. 